\title{
An experimental investigation of turbulent forced convection heat transfer by a multi- walled carbon-nanotube nanofluid
}

\author{
M. Piratheepan ${ }^{*}$ and T.N. Anderson \\ School of Engineering, Auckland University of Technology, Auckland 1142, New Zealand
}

\begin{abstract}
In this work a nanofluid based on multi-walled carbon nanotubes was formulated, and its heat transfer characteristics experimentally examined for turbulent flow in a straight tube. The experiments found that using the nanofluid resulted in an increase in pumping power and also a decrease in the observed convective heat transfer characteristics. This suggests that multi-walled carbon nanotube nanofluids in turbulent flows will actually impair heat transfer rather than improve it, and so may not be an appropriate heat transfer media in forced turbulent flows.
\end{abstract}

Keywords: nanofluid, turbulent, forced convection

\section{Introduction}

Introducing small particles into heat transfer fluids in order to increase the thermal performance of the fluid is not a new idea. More than a century ago Maxwell [1] published a theoretical work that showed the effective thermal properties of fluids could be improved by the addition of highly thermally conductive particles dispersed in a base fluid. However until recently these studies were limited to solid particles at millimetre or micrometre scale dispersed in a liquid media, the stability of such fluids is very poor and the particles tend to coagulate. However, in recent years, modern technologies have facilitated the manufacture of the particles down to nanometre scale. As such it is possible make nanoparticle dispersions in a base fluid that exhibit increased dispersion quality and stability [2]. In this regard, the term nanofluid was coined in the mid-1990's to describe a solid-liquid two phase mixture consisting of engineered nanometre-sized metallic, non-metallic or oxide particles suspended in a base liquid [3].

In an early study Choi et al [3] presented a theoretical analysis of copper metallic particle based nanofluids and concluded that it increased the effective thermal conductivity of the solutions significantly. Furthermore, during the past two decades numerous research works have examined the thermal properties of these nanofluids in the hope of improving the thermal

\footnotetext{
*Corresponding Author: pmahendr@aut.ac.nz
} 
characteristics of cooling liquids. Many of them concluded in showing the thermal conductivity of a base liquid increased by adding small particles in suspension [4].

However, limited work has been undertaken on forced convection heat transfer using nanofluids [5]. Pak et al [6] studied the forced heat convection heat transfer coefficient of nanofluids containing $\mathrm{Al}_{2} \mathrm{O}_{3}$ and $\mathrm{TiO}_{2}$ nanoparticles under turbulent flow. They found that Nusselt number increased with an increase in the volume fraction of nanoparticles and Reynolds number. Subsequently Eastman et al [7] reported an improvement in heat transfer coefficients with a $\mathrm{CuO}$ based nanofluid. In 2008 Williams [8] observed a considerable increase in heat transfer coefficient when $\mathrm{ZrO}_{2}$ based nanoparticle were used.

Additionally, many experimental studies have reported very high thermal conductivity for carbon nanotubes (CNT) [9, 10], therefore one might expect that a fluid suspension consisting of CNT would deliver better thermal properties than conventional liquids. In this respect, [11] applied a multi-walled carbon nanotube (MWCNT) based nanofluid to enhance the efficiency of a flat plate solar collector. However there is very limited work on forced convection heat transfer of MWCNT based nanofluids in turbulent flow [12]. Moreover, the improvements reported by Choi et al [13] could not be reproduced by subsequent studies on MWCNT based nanofluids [14].

In summary, there are a number of studies that have reported inconsistent results [6, 15-18] and also some studies showing a decrease in heat transfer coefficient after adding nanoparticles to the base fluids $[16,19]$. As such, where previous studies concentrated on laminar flow or various formulations of nanofluids, for this study, it was decided to investigate the forced convection heat transfer of a MWCNT nanofluid under turbulent flow conditions.

\section{Experimental Method}

To determine the convective heat transfer from the MWCNT nanofluid, a copper tube-in-tube heat exchanger was built with an inner and outer tube diameter of 1/4" and 1" respectively, as shown in Fig. 1. An entrance length of approximately 20 diameters of the inner tube was left outside the outer shell of the heat exchanger, to ensure fully developed turbulent flow through the inner pipe. Saturated steam, at approximately 4-bar, was condensed in the outer tube to provide a constant wall temperature to the nanofluid circulating through the smaller inner tube. A control valve at the pump was used to control the flow rate of the fluid by allowing fluid to be 
recirculated into the supply tank. Additionally, the temperature of the steam and the inlet and outlet temperatures of the heated inner tube were measured using T-type thermocouples $\left( \pm 0.3^{\circ} \mathrm{C}\right)$. The flow rate was measured by recording the time taken for a measured mass to be accumulated in a collection container.

\subsection{Validation of experimental apparatus}

In order to ensure that the experimental setup was able to accurately determine the convective heat transfer coefficients for turbulent flow in a tube, a preliminary experiment was conducted in which water was used as the heat transfer medium. From the inlet and outlet fluid temperature readings, as well as knowledge of the mass flow rate and specific heat of water, the heat transferred from the steam to the fluid $(Q)$ can be calculated. Now because the wall resistance of the copper inner tube is relatively small it was assumed to be negligible, hence the overall forced convection heat transfer coefficient, $h_{f c}$ can be calculated according to Newton's law of cooling as given in Equation 1.

$$
h_{f c}=\frac{Q}{\left(A * \Delta T_{l n}\right)}
$$

where $\Delta T_{l n}$ is the Log-Mean Temperature Difference

Fifteen sets of readings were taken under steady state conditions for each flow condition, and the mean fluid temperature value was used to determine the physical properties of the heat transfer fluid for each flow condition. This allowed the Nusselt number and Reynolds number values to be determined for the experiment.

Now to validate the experimental apparatus, the experimental values of Nusselt number were compared to those predicted by the Gnielinski empirical correlation [20] shown in Equation 2.

$$
N u=\frac{\frac{f}{8}(R e-1000) * P r}{1+12.7 \sqrt{\frac{f}{8}\left(\operatorname{Pr}^{2} / 3-1\right)}}
$$

For $0.7<\operatorname{Pr}<2000$ and $3000<\operatorname{Re}<5 * 10^{6}$

where the friction factor $(f)$ is given by Petukhov's correlation [21], as shown in Equation 3.

$$
f=\frac{1}{\left(1.8 \log _{10} \frac{R e}{6.9}\right)^{2}}
$$

In Fig. 2, it can be seen that the Nusselt numbers obtained from the experiment compare favourably with those computed by Gnielinski's empirical correlation. As such, the experimental apparatus should be able to accurately determine the heat transfer characteristics of the nanofluid. 


\subsection{Nanofluid Pre-preparation}

Nanofluids are not simply liquid-solid mixtures, but have special requirements. In this regard stability, homogenous suspension, durability of the suspensions and agglomeration effects should be considered while making such fluids.

As MWCNT particles are hydrophobic in nature their dispersability in water is expected to be poor. However, adding a surfactant that has hydrophobic and hydrophilic functional groups may improve the stability of the liquid [22]. Hence, it was decided to investigate the stability and the dispersion of the MWCNT nanoparticles in the water using a surfactant. Rastogi et al [22] compared the dispersion of MWCNT particles in water using four different surfactants: Triton X-100, Tween 20, Tween 80 and Sodium dodecyl sulphate, and found that Triton X-100 had the greatest ability to disperse MWCNT nanoparticles. In addition to that, sonication of the mixture appears to improve the dispersion ability of the particle in the fluid [23, 24].

In order to minimize the agglomeration of nanoparticles and to study the stability of the MWCNT nanofluid, it was decided to use Triton X-100 surfactant in conjunction with sonication to prepare the MWCNT nanofluid. In undertaking this analysis different compositions, as shown in Table 1, and different sonication times were tested.

Four portions of the each sample (MWCNT with an average diameter: 10-40 nm, length: 1$25 \mu \mathrm{m}$, purity by weight: $93 \% \mathrm{~min}$, specific surface area: $150-250 \mathrm{~m}^{2} / \mathrm{g}$ ) [25] were sonicated for 10, 20, 30 and 40 minutes in a 2L 100W ultrasonic bath. Samples were stored in stoppered test tubes to be observed for a few days, to assess their stability over time. As can be seen in Fig. 3 the samples of the fourth experimental set, without any surfactant, MWCNT's precipitated regardless of the sonication time. This is understandable due to the hydrophobic nature of the MWCNT, which implies particle dispersion will be poor.

Additionally, the MWCNT particles precipitated more rapidly under 10 minutes sonication compared to the samples sonicated for longer periods. This illustrates the effect of the sonication time on producing a homogenous nanofluid. Furthermore, if we consider the effect of surfactant on the dispersion, as shown in Fig. 4, samples of fluid sonicated for 30 minutes with a lower surfactant to MWCNT ratio (3 and 5) showed some agglomeration whilst samples of condition 1 and 2 were more homogenous. 
To understand the properties of the nanofluid better dried samples of untreated and surfactant treated MWCNT particles were examined with a scanning electron microscope (SEM). In Fig. 5 it can be seen that the MWCNT nanoparticles appear to be coated with what we believe to be, surfactant and are slightly less tangled in comparison to the untreated sample shown in Fig. 6. Finally, a magnified image, Fig. 7, was used to confirm the diameter of the nanotubes as specified by the supplier.

\subsection{Bulk nanofluid preparation}

Based on the above stability experiment, it was decided to use 30 minutes of ultrasonic mixing to form a stable mixture. Although both the first and second sample solutions were stable enough to conduct the experiment, the first run of the second sample fluid ( $1 \mathrm{~g}$ of MWCNT and $2.5 \mathrm{ml}$ surfactant in $1 \mathrm{~L}$ of water) through the test rig resulted in excessive loading on the pump and some agglomeration after pumping. Hence, it was decided to lower the nanoparticle loading while keeping a similar or higher surfactant to MWCNT volume ratio, by doing this one would expect the nanofluid to be more homogenous.

In order to prepare this solution, $0.24 \mathrm{~g}$ of MWCNT and $10 \mathrm{ml}$ Triton X-100 were mixed with $990 \mathrm{ml}$ of water for 30 minutes in the ultrasonic bath. Hence the volume ratio of the MWCNT to surfactant was kept at 1:90 while the MWCNT volume fraction in the final solution was $0.011 \%$ (True density of the nanoparticle is $2.16 \mathrm{~g} / \mathrm{cm}^{3}$ ). This process was repeated until 40 litres of nanofluid was prepared for use in the system. Subsequently, the same experimental testing and measurement procedure used in the water experiments was performed.

\section{Analysis of Nanofluid and Results}

In order to find the corresponding Nusselt numbers of the nanofluid at various flow rates, it is essential to calculate the thermo-physical properties of the nanofluid. For this work, the bulk properties of the nanofluid were calculated assuming they were a homogeneous liquid.

The heat capacity of the nanofluid can be found by calculating the heat capacity of the watersurfactant mixture, then using that value to calculate heat capacity of the MWCNT nanofluid by a simple mixing model. However, as there is no available data on the specific heat capacity of the surfactant, and the amount of surfactant used is small compared to the mass of water, the effect of surfactant on the heat capacity is assumed to be equal to water, so that the heat capacity of the nanofluid can be calculated using Equation 4 [26] . 


$$
\rho_{n f} * C_{p n f}=(1-\varnothing) C_{p f} * \rho_{f}+\emptyset * \rho_{p} C_{p p}
$$

where the density of the nanofluid $\rho_{n f}$ can be calculated using a mixing model as shown in Equation 5 [11] and $C_{p n f}$ is the heat capacity of the nanofluid while $C_{p f}$ and $C_{p p}$ are the heat capacities of water and nanoparticles respectively.

$$
\rho_{n f}=(1-\varnothing) \rho_{f}+\varnothing \rho_{p}
$$

where $\rho_{n}$ is the density of the nanoparticle (taken to be $2.16 \mathrm{~g} / \mathrm{cm}^{3}$ ) [27] while the density of the water is $\rho_{f}$ is based on the bulk temperature and $\phi$ is the volume fraction of nanoparticles.

The dynamic viscosity of the fluid can be calculated using the correlation for non-spherical particles suggested by Brenner et al [28], considering the shape effects, as shown in Equation 6 .

$$
\mu_{n f}=\mu_{f}(1+\eta \varnothing)
$$

where $\eta=\frac{0.312 r}{\ln 2 r-1.5}+2-\frac{0.5}{\ln 2 r-1.5}-\frac{1.872}{r}$

and $\mu_{f}$ is the viscosity of the base fluid and $r$ is the aspect ratio of the particle, assumed to be 100 based on the suppliers data and the SEM images.

The relative viscosity of the base fluid was assumed to be the same as water, although there was surfactant dissolved in the water, the amount was not sufficient enough to change the viscosity of the resultant solution significantly [29]. Therefore the Reynolds number for the nanofluid can be determined from Equation 7

$$
R e=\frac{\rho_{n f} * v * D_{H}}{\mu_{n f}}
$$

where $D_{H}$ is the diameter of the pipe; and $v$ is the velocity of the fluid along the pipe, found from the mass flow rate. As such Newton's law of cooling allows the forced convection heat transfer coefficient to be determined as described previously.

To non-dimensionalise the results, and express them in terms of the Nusselt number, the thermal conductivity can be calculated using Hamilton and Crosser's modified Maxwell's model [30] for the effective thermal conductivity of spherical and non-spherical particles by using a shape factor as given in Equation 8. The function consists of thermal conductivities of both solid and liquid phases, volume fraction and the shape of the dispersed particles.

$$
\lambda_{n f}=\lambda_{f}\left[\frac{\lambda_{p}+(n-1) \lambda_{f}-(n-1) \emptyset_{p}\left(\lambda_{f}-\lambda_{p}\right)}{\lambda_{p}+(n-1) \lambda_{f}+\varnothing_{p}\left(\lambda_{f}-\lambda_{p}\right)}\right]
$$

Where $\mathrm{n}=6$ for cylindrical particles, $\emptyset_{p}$ is the particle volume fraction $\lambda_{f}$ is the thermal conductivity of water 
$\lambda_{p}$ is the thermal conductivity of the nanoparticle

and $\lambda_{n f}$ is the thermal conductivity of the nanofluid

The thermal conductivity of the MWCNT nanoparticles is in the range of 2000W/mK [31]

while the thermal conductivity of the water was determined based on the bulk temperature.

By comparing the dimensionless parameters of water and the MWCNT nanofluid, the suitability of the nanofluid for forced convection heat transfer can be examined. From Fig. 8 we can see that the Nusselt number and corresponding Reynolds number for the nanofluid are significantly lower than those of water at the same flow condition under steady state.

Furthermore, it was observed that the nanofluid imparted a high loading on the pump, meaning that the pumping power to achieve a similar Reynolds number was significantly higher with a nanofluid than that of water. This is a significant observation in terms of using the nanofluid as a heat transfer fluid such as this may demand additional energy input not needed if water is used.

\section{Conclusion}

In this work, the forced convection heat transfer coefficient of a MWCNT nanofluid under fully developed turbulent flow was experimentally examined. By analysing both water and MWCNT nanofluid on the same equipment, it was found that operational conditions (such as pumping power) and thermophysical characteristics of the fluid vary significantly from the base fluid, water. However, the MWCNT based nanofluid did not improve the heat transfer characteristics; instead there was a significant drop in heat transfer capabilities. This suggests that MWCNT nanofluids in turbulent flows will actually impair heat transfer rather than improve it and so may not be an appropriate heat transfer media in forced turbulent flows.

\section{References}

[1] J. C. Maxwell, A treatise on electricity and magnetism, 2nd edition ed. vol. 1. Oxford,UK: Clarendon Press, 1881.

[2] Z. Haddad, C. Abid, H. F. Oztop, and A. Mataoui, "A review on how the researchers prepare their nanofluids," International Journal of Thermal Sciences, vol. 76, pp. 168189, 2014. 
[3] S. Choi and J. A. Eastman, "Enhancing thermal conductivity of fluids with nanoparticles," presented at the ASME International Mechanical Engineering Congress \& Exposition, Argonne, Illinois, 1995.

[4] Y. Li, J. E. Zhou, S. Tung, E. Schneider, and S. Xi, "A review on development of nanofluid preparation and characterization," Powder Technology, vol. 196, pp. 89-101, 2009.

[5] L. Godson, B. Raja, D. Mohan Lal, and S. Wongwises, "Enhancement of heat transfer using nanofluids-An overview," Renewable and Sustainable Energy Reviews, vol. 14, pp. 629-641, 2010.

[6] B. C. Pak and Y. I. Cho, "Hydrodynamic and heat transfer study of dispersed fluids with submicron metallic oxide particles," Experimental Heat Transfer an International Journal, vol. 11, pp. 151-170, 1998.

[7] J. Eastman, U. Choi, S. Li, G. Soyez, L. Thompson, and R. DiMelfi, "Novel thermal properties of nanostructured materials," Journal of Metastable and Nanocrystalline Materials, vol. 2, pp. 629-634, 1999.

[8] W. Williams, L.-W. Hu, and J. Buongiorno, "Experimental investigation of turbulent convective heat transfer and pressure loss of alumina/water and zirconia/water nanoparticle colloids (nanofluids) in horizontal tubes," Journal of Heat Transfer, vol. 130, p. 042412, 2008.

[9] S. Berber, Y.-K. Kwon, and D. Tomanek, "Unusually high thermal conductivity of carbon nanotubes," Physical Review Letters, vol. 84, p. 4613, 2000.

[10] S. Maruyama, "A molecular dynamics simulation of heat conduction in finite length SWNTs," Physica B: Condensed Matter, vol. 323, pp. 193-195, 2002.

[11] T. Yousefi, F. Veisy, E. Shojaeizadeh, and S. Zinadini, "An experimental investigation on the effect of MWCNT- $\mathrm{H}_{2} \mathrm{O}$ nanofluid on the efficiency of flat-plate solar collectors," Experimental Thermal and Fluid Science, vol. 39, pp. 207-212, 2012.

[12] W. Rashmi, M. Khalid, A. Ismail, R. Saidur, and A. Rashid, "Experimental and numerical investigation of heat transfer in CNT nanofluids," Journal of Experimental Nanoscience, pp. 1-19, 2013.

[13] S. Choi, Z. Zhang, W. Yu, F. Lockwood, and E. Grulke, "Anomalous thermal conductivity enhancement in nanotube suspensions," Applied Physics Letters, vol. 79, pp. 2252-2254, 2001.

[14] W. Y. A. Xie, "A Review on Nanofluids: Preparation, Stability Mechanisms, and Applications," Journal of Nanomaterials, vol. 2012, 2012. 
[15] R. Chein and J. Chuang, "Experimental microchannel heat sink performance studies using nanofluids," International Journal of Thermal Sciences, vol. 46, pp. 57-66, 2007.

[16] Y. Ding, H. Chen, Y. He, A. Lapkin, M. Yeganeh, L. Siller, and Y. V. Butenko, "Forced convective heat transfer of nanofluids," Advanced Powder Technology, vol. 18, pp. 813-824, 2007.

[17] J. Lee and I. Mudawar, "Assessment of the effectiveness of nanofluids for single-phase and two-phase heat transfer in micro-channels," International Journal of Heat and Mass Transfer, vol. 50, pp. 452-463, 2007.

[18] I. C. Nelson, D. Banerjee, and R. Ponnappan, "Flow loop experiments using polyalphaolefin nanofluids," Journal of Thermophysics and Heat Transfer, vol. 23, pp. 752-761, 2009.

[19] Y. Yang, Z. G. Zhang, E. A. Grulke, W. B. Anderson, and G. Wu, "Heat transfer properties of nanoparticle-in-fluid dispersions (nanofluids) in laminar flow," International Journal of Heat and Mass Transfer, vol. 48, pp. 1107-1116, 2005.

[20] V. Gnielinski, "New equations for heat and mass-transfer in turbulent pipe and channel flow," International Chemical Engineering, vol. 16, pp. 359-368, 1976.

[21] Y. A. Cengel, Heat \& mass transfer: a practical approach: Tata McGraw-Hill Education, 2007.

[22] R. Rastogi, R. Kaushal, S. K. Tripathi, A. L. Sharma, I. Kaur, and L. M. Bharadwaj, "Comparative study of carbon nanotube dispersion using surfactants," Journal of Colloid and Interface Science, vol. 328, pp. 421-428, 2008.

[23] J. Liu, A. G. Rinzler, H. Dai, J. H. Hafner, R. K. Bradley, P. J. Boul, A. Lu, T. Iverson, K. Shelimov, and C. B. Huffman, "Fullerene pipes," Science, vol. 280, pp. 1253-1256, 1998.

[24] X. Li, D. Zhu, and X. Wang, "Evaluation on dispersion behavior of the aqueous copper nano-suspensions," Journal of Colloid and Interface Science, vol. 310, pp. 456-463, 2007.

[25] Playwithcarbon.com. http://www.playwithcarbon.com/carbon-nanotubes-1l/ (cited 22/05/2014).

[26] Y. Xuan and W. Roetzel, "Conceptions for heat transfer correlation of nanofluids," International Journal of Heat and Mass Transfer, vol. 43, pp. 3701-3707, 2000.

[27] S. Kanagaraj, F. R. Varanda, T. V. Zhil’tsova, M. S. A. Oliveira, and J. A. O. Simões, "Mechanical properties of high density polyethylene/carbon nanotube composites," Composites Science and Technology, vol. 67, pp. 3071-3077, 2007. 
[28] H. Brenner and D. W. Condiff, "Transport mechanics in systems of orientable particles. IV. convective transport," Journal of Colloid and Interface Science, vol. 47, pp. 199264, 1974.

[29] L. Qiao, "A Study of Triton X Series Nonionic Surfactant Solutions" PhD Thesis, University of Auckland, Auckland, 1996.

[30] R. Hamilton and O. Crosser, "Thermal conductivity of heterogeneous two-component systems," Industrial \& Engineering Chemistry Fundamentals, vol. 1, pp. 187-191, 1962.

[31] C. A. Nieto de Castro, S. M. S. Murshed, M. J. V. Lourenço, F. J. V. Santos, M. L. M. Lopes, and J. M. P. França, "Enhanced thermal conductivity and specific heat capacity of carbon nanotubes ionanofluids," International Journal of Thermal Sciences, vol. 62, pp. 34-39, 2012. 
Table 1 Composition of the sample experiments

\begin{tabular}{ccc}
\hline Experiment & $\begin{array}{c}\text { Amount of surfactant in } \\
\text { 1l solution }\end{array}$ & $\begin{array}{c}\text { MWCNT Concentration } \\
\mathrm{g} / \mathrm{l}\end{array}$ \\
\hline 1 & $5 \mathrm{ml}$ & 1 \\
\hline 2 & $2.5 \mathrm{ml}$ & 1 \\
\hline 3 & $1 \mathrm{ml}$ & 1 \\
\hline 4 & $0 \mathrm{ml}$ & 1 \\
\hline 5 & $2.5 \mathrm{ml}$ & 2 \\
\hline
\end{tabular}




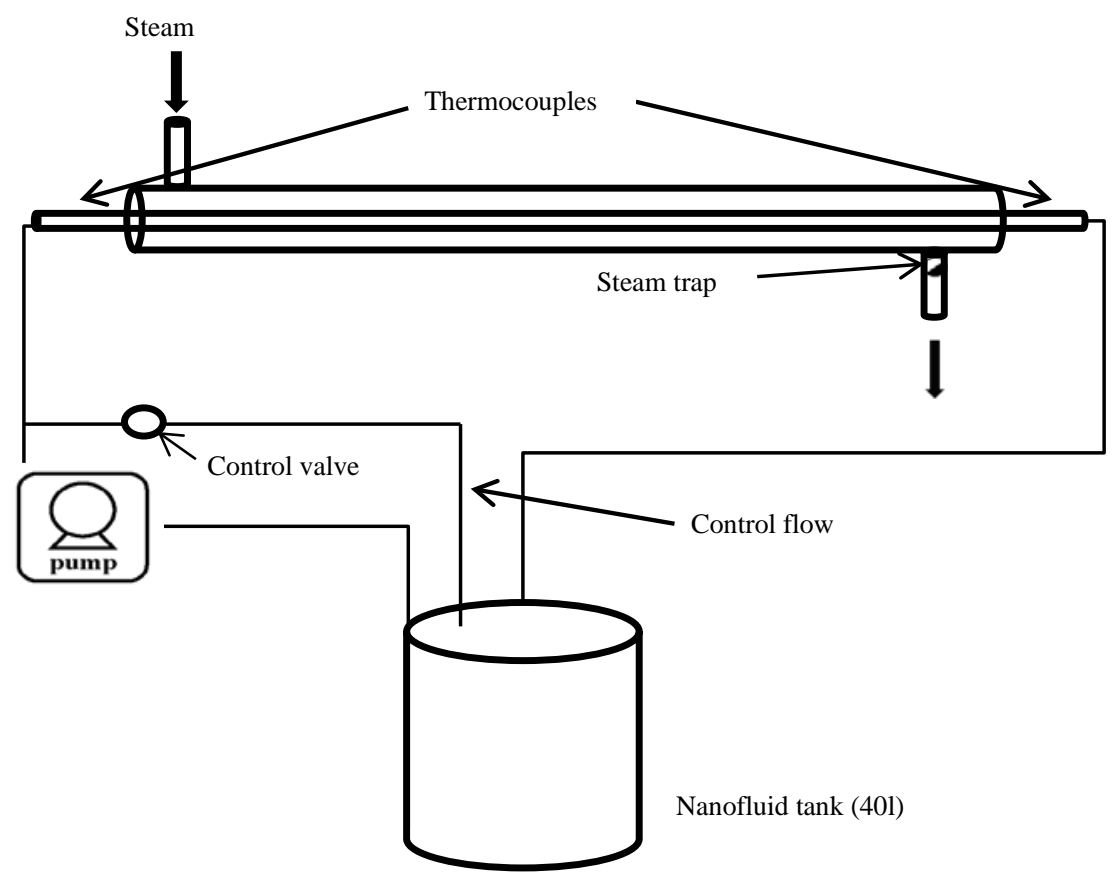

Fig. 1 Experimental setup 


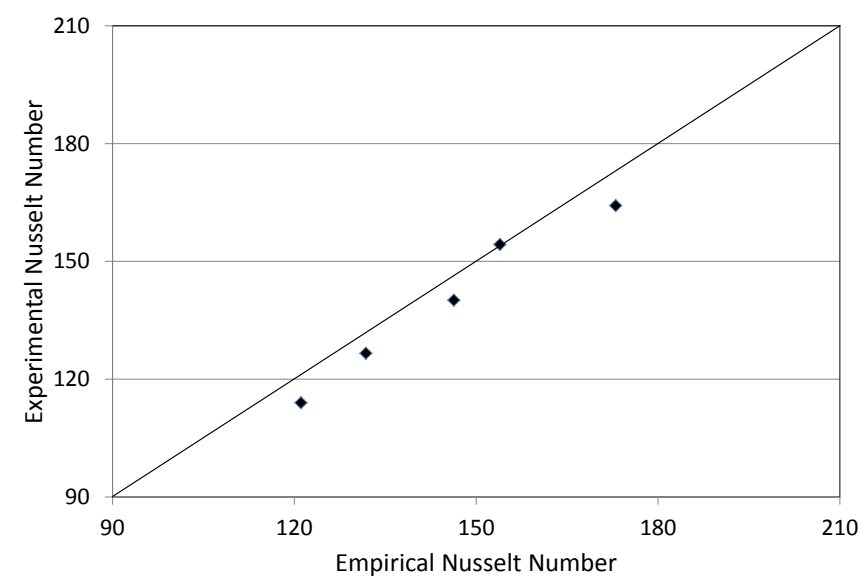

Fig. 2 Experimental versus empirical Nusselt number values 


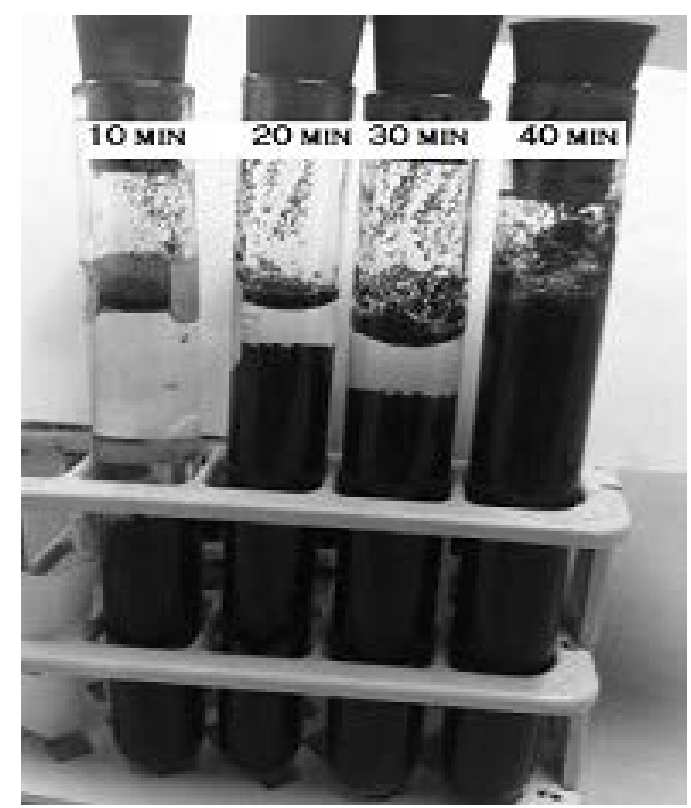

Fig. 3 Samples without surfactant with different sonication time 


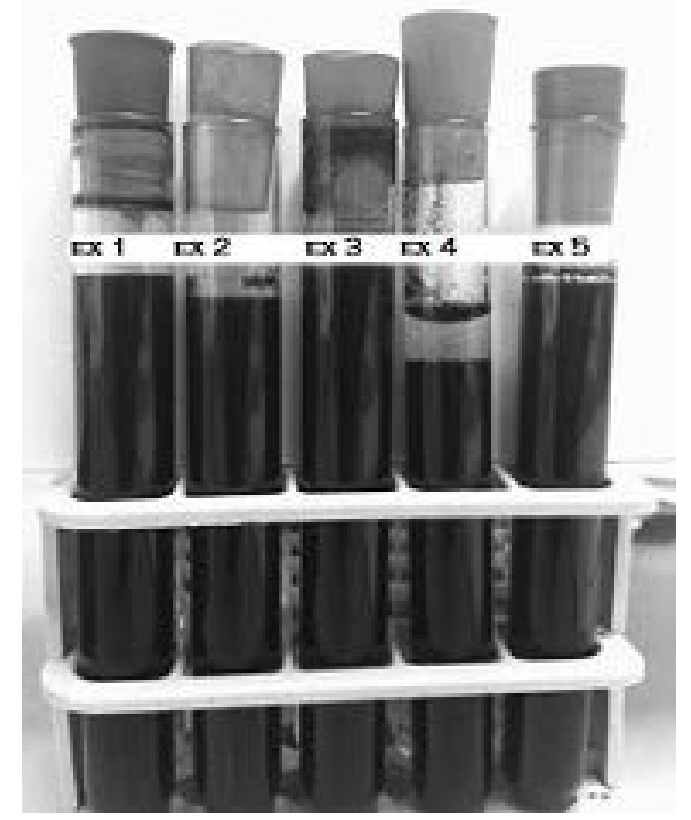

Fig. 4 Samples with surfactant with different sonication time 


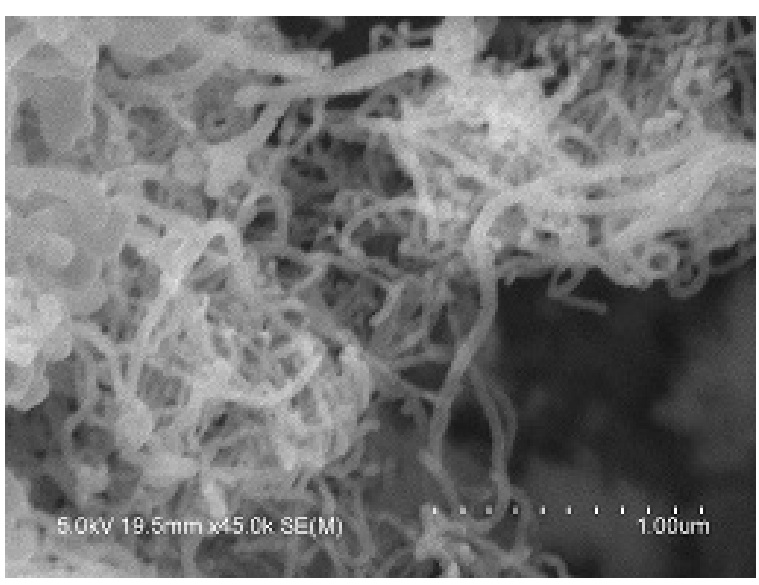

Fig. 5 Surfactant treated sample 


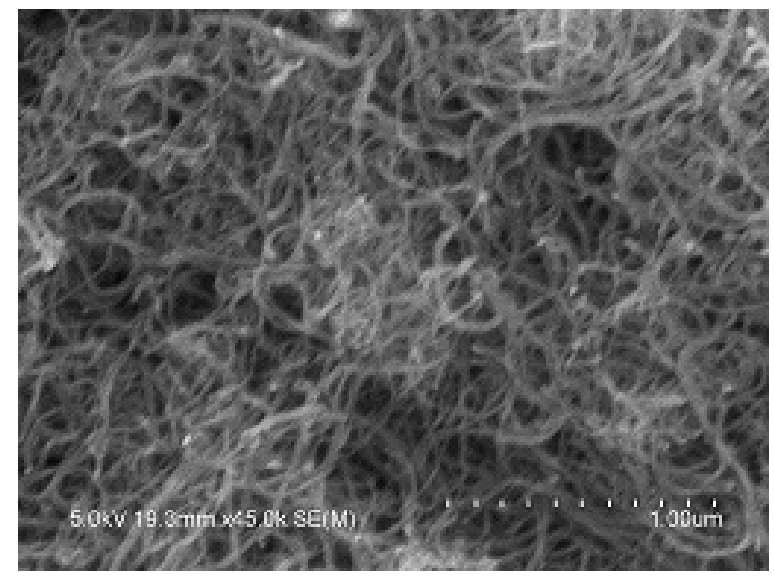

Fig. 6 Untreated sample 


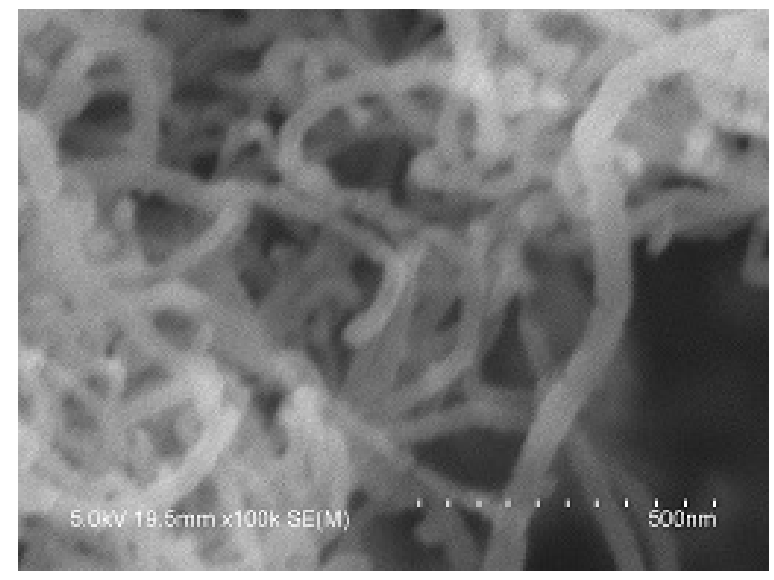

Fig. 7 Magnified view of surfactant treated sample 


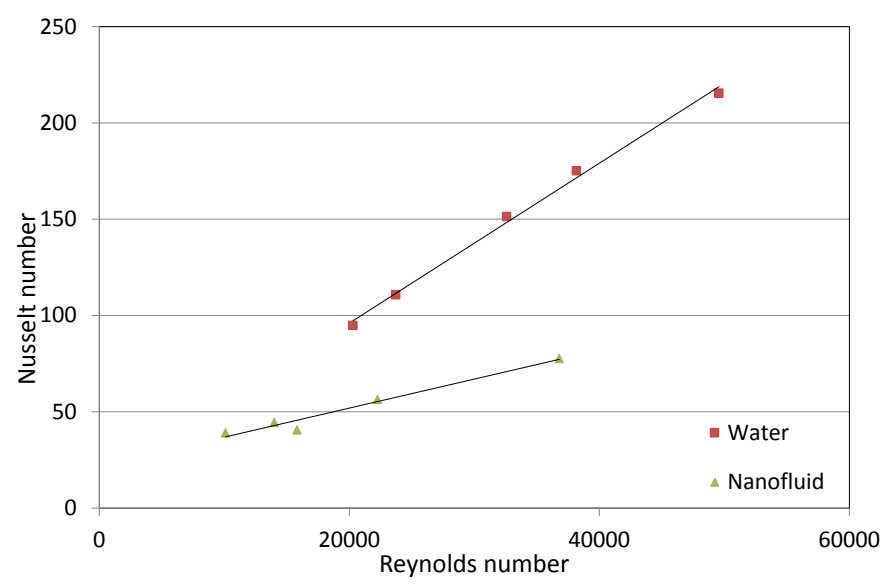

Fig. 8 Comparison of water and nanofluid heat transfer characteristics 